\title{
Improving preparedness of junior doctors to manage patients with diabetes: a pilot educational programme from ward-based pharmacists
}

\author{
STEPHEN WARD, ${ }^{1}$ GEMMA WASSON²
}

\begin{abstract}
Background: Diabetes is a complex condition and junior doctors can feel underprepared when tasked with safely prescribing insulin. Hyperglycaemia is known to increase mortality and morbidity, yet a British study in 2008 demonstrated that a quarter of doctors responding to the survey did not feel confident enough to take the main initiative to control blood glucose for a patient under their care in hospital. Diabetes learning resources are widely available, yet few offer the opportunity to link undergraduate theory with practical prescribing tasks. Clinical pharmacists can play an important role in providing this type of practical support and in the formative development of safe prescribing for junior doctors. This paper describes an initiative from a hospital pharmacy team to support Foundation Year doctors (FY1s) with safe insulin prescribing.

Methods: The team from the Belfast Trust designed a wardbased teaching session which could be used by clinical pharmacists to help newly qualified doctors on their wards. These sessions, known as SIPS (Safe Insulin Prescribing Sessions), focused on three key areas: documentation, insulin product range and resources. The aim was to assess if SIPS had an impact on confidence levels for different aspects of insulin prescribing. This pilot educational intervention was carried out with 19 junior doctors. After the session each doctor was contacted to complete a short online questionnaire ranking their confidence and knowledge levels in managing inpatients prescribed insulin before and after the pharmacist SIPS.
\end{abstract}

Results: After completing the ward-based teaching there were statistically significant increases in the self-ranked con-

Teacher Practitioner Pharmacist, Belfast Health and Social Care Trust, Belfast, UK

Clinical Pharmacist, Belfast Health and Social Care Trust, Belfast, UK

Address for correspondence: Mr Steven Ward

Pharmacy Department, Royal Group of Hospitals, Belfast Health and Social

Care Trust, Grosvenor Road, Belfast BT12 6BA, Northern Ireland

Tel: +44 (0)2890632268

E-mail: Stephen.ward@belfasttrust.hscni.net

https://doi.org/10.15277/bjd.2017.151 fidence and knowledge levels of junior doctors regarding insulin prescribing.

Conclusions: This pilot demonstrates that ward-based teaching from a pharmacist can support junior doctors in managing diabetes. A larger study would be needed to confirm whether this translates into better management of inpatients with diabetes.

Br J Diabetes 2017;17:152-155

Key words: clinical pharmacy, inter-professional education, Northern Ireland, patient safety, quality improvement, ward-based teaching, insulin prescribing

\section{Background}

With an ever increasing evidence base for multiple therapeutic interventions, diabetes is a complex condition that requires junior doctors to acquire adequate knowledge and skills. Since 1996 the number of people living with diabetes has more than doubled and in the UK more than 3.6 million people live with the condition. ${ }^{1}$ Therefore, regardless of their eventual expertise, it is important that junior doctors are confident in its management, particularly in the prescribing of insulin.

Unfortunately many junior doctors do not feel confident enough to apply theory to practice and to manage this chronic disease with the array of insulin products and devices currently available. The potential for errors in prescribing due to lack of confidence and knowledge may lead to serious adverse events such as hypoglycaemia or hyperglycaemia. Hyperglycaemia is known to increase mortality and morbidity in addition to higher health costs. ${ }^{2}$ A British study undertaken in 2008 revealed that a quarter of doctors responding to a survey would not take the main initiative to control blood glucose for a patient under their care in hospital. ${ }^{3}$ The study also identified a clear desire for further training in relatively fundamental aspects of diabetes.

Resources providing opportunities to improve diabetes knowledge and access to guidelines are widely available. However, few provide the opportunity to link theory with fundamental prescribing tasks such as completing insulin charts, understanding and interpreting local policies and differentiating between commonly used insulin products. ${ }^{4}$ Clinical pharmacists can play an important role in providing this type of practical support and in the formative development of safe prescribing for junior doctors. ${ }^{5}$ 
The EQUIP study was an in-depth investigation into the causes of prescribing errors by foundation trainees and how this relates to their medical education. ${ }^{6}$ Respondents identified the role of pharmacists in reducing the gap between theoretical instruction in pharmacology and practical prescribing.

Within the Belfast Trust, the need for additional training in the prescribing of insulin was identified during pharmacy workshops provided for final year medical students (FYOs). The Clinical Pharmacy team developed a 3-hour FYO workshop focusing on practical prescribing scenarios categorised as high risk by local medicines safety teams. The workshops included simulated case studies requiring the FYO student to discuss medicine use with patients, prescribe admission drug charts and use local guidelines to safely prescribe high-risk medicines. During these sessions FYOs were asked to identify additional learning needs in advance of their first year as a doctor. Insulin prescribing was their main concern, with $64 \%$ of students identifying this as their main learning need, particularly the practical aspects such as documentation, knowledge of insulin products and access to guidelines.

The aim of this pilot educational intervention from a clinical pharmacy team was to support Foundation Year doctors (FY1s) with safe insulin prescribing. The primary objective was to improve the practical preparedness of junior doctors to manage inpatients with insulintreated diabetes.

\section{Methods}

The endocrine specialist pharmacist in the Belfast Trust was tasked with designing a short educational session that could be used by other clinical pharmacists to assist junior doctors starting on their wards. Based on feedback from the FYO workshops, we were aware that educational concerns mainly related to more practical aspects of insulin prescribing (i.e. insulin products, documentation and accessing resources/guidelines). We were therefore keen to provide ward-based teaching in a context that could meet these learning needs.

The overarching theme for this session focused on one question: "If you, as an endocrine specialist pharmacist, had 30 minutes with a newly qualified doctor, what do you think would be important to show them on the ward to support safe prescribing of insulin?" From this initial question, the pharmacy team were able to establish a structure based on the identified learning needs (Table 1):

- Documentation (includes prescribing charts and blood glucose monitoring charts).

- Insulin products (wide range of products commonly stocked on the ward and those not stocked which a patient may be receiving when admitted).

- Resources (including local policies and regional/national guidelines).

This structure was used to design an initial training workshop for clinical pharmacists. The project summary was shared with the clinical pharmacy team across the Trust and clinical pharmacists were invited to participate in the pilot. Those agreeing to participate were asked to attend the initial workshop before arranging a ward-based teaching session with the FY1(s) allocated to their specific ward. FY1s were given structured prescribing support with a pharmacist for $30 \mathrm{~min}$
Table 1 Structure for Safe Insulin Prescribing Session

Documentation - Demonstrate key areas of drug chart. There should be notification on the front that insulin is prescribed. Injectable section must reference Glucose monitoring/ Insulin Prescribing Chart. (GMIPC)

- Explain each section of GMIPC

- Highlight other circumstances requiring full details e.g. record of insulin pump, patients who carb-count. Patient is a key source of information

- Insulin must be prescribed for each individual day- not always happening

- Explain rationale regarding correction doses as a finding strategy. These doses are recorded in the same daily box

- Do not omit insulin - critical list medicine adjust dose/give food/seek senior advice

Resources

- Highlight Trust policies and where to access e.g. Hypoglycaemia, DKA/HONK, steroidinduced diabetes

- Provide information relating to writing up a fluid balance chart e.g. DKA

- Show where to find the FY1 Handbook and section relating to insulin

- Talk through the practical information provided on the back of the GMIPC e.g. dosage adjustment

- Show the poster on how to make up a 50 unit in $50 \mathrm{ml}$ insulin infusion (from Safe Use policy)

- Highlight access to useful information e.g. show diabetes UK insulin wallchart

- Show the FY1 a typical "passport card" and emphasise that they should always check this with patient if prescribing insulin

Insulin products

- Drug-room - show insulin syringes and reinforce use. Show the different preparations available e.g. vials, cartridges, pre-filled pens

- Explain that not every injection for diabetes will be insulin e.g. exenatide, liraglutide

- Majority of insulin strengths will be 100 units/ $\mathrm{ml}$. Explain exceptions including insulin degludec (Tresiba ${ }^{\circledR}$ ) which has a 100 units $/ \mathrm{ml}$ and a 200units/ml preparation and insulin glargine (Toujeo ${ }^{\circledR}$ ) strength of 300 units $/ \mathrm{ml}$

- Refer to hyperkalaemia kits if using insulin for high potassium and syringe within

- When talking about brand names \& device explain what the numbers mean for mixes. Ensure they are aware that Humalog Mix $50^{\circledR}$ is not the same as Humalog ${ }^{\circledR}$ and is not usually prescribed three times a day

on the ward during the first two months after qualifying. The session known as SIPS (Safe Insulin Prescribing Session) focused on the three key areas noted above (documentation, insulin products and resources).

Following the SIPS, FY1s were asked to retrospectively complete an online survey (5-point Likert quality scale ranging from very poor 
Table 2 Junior doctors' knowledge of insulin types and their confidence in insulin prescribing

\begin{tabular}{llllll}
\hline $\begin{array}{l}\text { Self-reported } \\
\text { confidence } \\
\text { and knowledge } \\
\text { levels }\end{array}$ & $\begin{array}{l}\text { Percentage } \\
\text { reporting } \\
\text { pre-SIPS }\end{array}$ & $\begin{array}{l}\text { Percentage } \\
\text { reporting } \\
\text { post-SIPS }\end{array}$ & Mann-Whitney results \\
$\begin{array}{l}\text { Good or excellent } \\
\text { ability to identify } \\
\text { different insulin } \\
\text { products }\end{array}$ & $8.3 \%$ & $83.3 \%$ & 15 & -3.26 & 0.001 \\
$\begin{array}{l}\text { Good or excellent } \\
\text { ability to manage } \\
\text { insulin patients }\end{array}$ & $33.3 \%$ & $100 \%$ & 18 & -3.08 & 0.002 \\
$\begin{array}{l}\text { Good or excellent } \\
\text { ability to access } \\
\text { policies/guidelines }\end{array}$ & $8.3 \%$ & $100 \%$ & 4.5 & -3.87 & 0.0001 \\
$\begin{array}{l}\text { Good or excellent } \\
\text { ability to recognise } \\
\text { insulin prescribing } \\
\text { risks }\end{array}$ & $42 \%$ & & & & \\
\hline
\end{tabular}

to excellent), ranking their confidence and knowledge levels in managing inpatients prescribed insulin before and after the pharmacist SIPS.

In the small survey, each junior doctor who had participated in the study was asked four specific questions:

1. How would you rate your ability to identify the different types of insulin you see in use on the wards (e.g. short-acting, biphasic and long-acting insulins)?

2. How would you rate your confidence in managing diabetic inpatients on subcutaneous insulin, including making insulin dose adjustments depending on the patient's blood glucose level?

3. How would you rate your confidence in accessing useful policies/guidelines to support your insulin prescribing?

4. How would you rate your confidence in recognising the risks associated with insulin prescribing?

The data compiled during the survey was anonymised. Two weeks after the survey was sent out a reminder email was sent to all junior doctors who had participated in the study.

\section{Results}

Ten pharmacists attended the original training. Nineteen FY1s were provided with ward-based teaching, 12 of whom completed the online questionnaire, giving a response rate of $63 \%$.

We ran a Mann-Whitney $U$ test to evaluate the difference in the responses to the 5 -Likert scale question and found a significant effect of SIPS for all four questions. Comparison was also made with the percentage of respondents who reported their confidence level as good or excellent for each question before and after SIPS (see Table 2).

\section{Discussion}

After completing the ward-based teaching there were statistically significant increases in the self-ranked confidence and knowledge

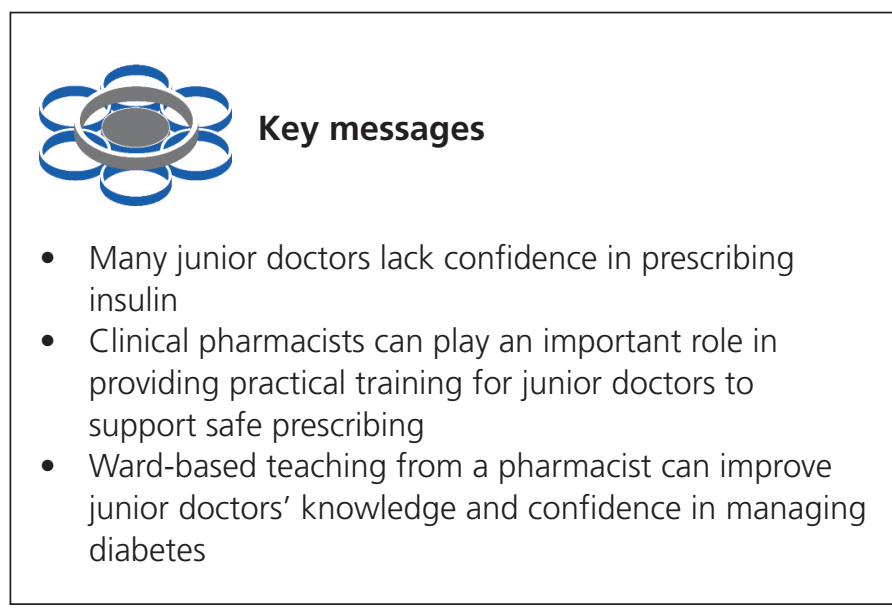

levels of junior doctors regarding diabetes management. This included improvements in identifying different types of insulin, making insulin dose adjustments and accessing useful policies and guidelines. Improving confidence levels for these prescribing practicalities is important because it provides contextual knowledge, and prescribing errors are often related to these practicalities. ${ }^{7}$ Learning in an applied setting on the ward can help prevent practical errors such as those which occur during the transcription process and errors made under time pressure. This dynamic form of practical wardbased learning has also been shown to improve certain clinical skills in students and residents. ${ }^{8}$ It is worth noting that the pilot is limited in that it does not fulfil the standard definition of ward-based learning. A number of important factors such as exposure to patients, feedback and supervision are lacking. Crucially, patient contact early in medical education can improve both biochemical and clinical knowledge. $^{9}$

Further development of this pilot would benefit from qualitative data to analyse in addition to the confidence levels. Semi-structured interviews or focus groups could be used to explore the training in the context of the learning environment. Why did the FY1s feel more confident prescribing insulin after this session? What are the implications of this increased confidence (for example, are they less likely to avoid prescribing insulin and hence avoid unnecessary delays to a critical medicine)? Do they think this training would be equally effective in a workshop setting? If this is not the case, what aspects of the ward-based environment helped support their learning? Other methods of insulin prescribing education are available, such as e-learning and case-based discussions, and it would be important to objectively assess ward-based teaching against these methodologies.

\section{Limitations of the study}

The study involved a group of pharmacists within the Trust who volunteered to participate in the education programme. This number therefore dictated the eventual number of participating junior doctors who could respond to the online survey. With additional resources, a study of this nature would benefit from a larger group of participating pharmacists and could include additional measurable outcomes such as clinical scenarios administered pre- and postintervention. 
As mentioned above, this pilot would benefit from qualitative data. In terms of translation of care, it would be useful to include pre- and post-incident data; however, the current incident reporting system does not categorise or identify individual staff involved. Similar studies should also consider coordinating data collection with the National Diabetes Inpatient Audit to provide measurable outcomes.

\section{Conclusion}

This pilot demonstrates that ward-based teaching delivered by a pharmacist can improve junior doctors' knowledge and confidence in managing patients with insulin-treated diabetes. A larger study would be needed to confirm whether this translates into better management of inpatients with diabetes.

Acknowledgements: The authors would like to thank the Belfast Trust Clinical Pharmacy team for their support of the FY1 pharmacy training programme. Particular thanks to those who volunteered for the insulin sessions and provided expertise and enthusiasm.

\section{Conflict of interest: None \\ Funding: None}

\section{References}

1. Diabetes UK. Key facts and stats https://www.diabetes.org.uk/Professionals/Position-statements-reports/Statistics (accessed 16 Jan 2017).
2. Desphande AD, Harris-Hayes M, Schootman M. Epidemiology of diabetes and diabetes-related complications. J Am Phys Ther Assoc 2008;88:1254-64. https://dx.doi.org/10.2522\%2Fptj.20080020

3. George JT, Warriner DA, Jeffrin A, et al. Training tomorrow's doctors in diabetes: self-reported confidence levels, practice and perceived training needs of post-graduate trainee doctors in the UK. A multi-centre survey. BMC Med Educ 2008;8:22. http://dx.doi.org/10.1186/1472-6920-8-22

4. Kelly NAA, Brandom KG, Mattick KL. Improving preparedness of medical students and junior doctors to manage patients with diabetes. BMJ Open Diabetes Res Care 2015;3(1).

http://dx.doi.org/10.1136/bmjdrc-2015-000116

5. Ward S, Wasson G. Bridging the gap: improving safe prescribing from university to workplace. Int J Clin Pharmacy 2016;38:1023-6. http://dx.doi.org/10.1007/s11096-016-0346-x

6. Dornan T, Ashcroft $D$, Heathfield $H$, et al. An in depth investigation into causes of prescribing errors by foundation trainees in relation to their medical education: EQUIP study. 2009. http://www.gmcuk.org/FINAL_Report_prevalence_and_causes_of_prescribing_errors.pdf 28935150.pdf (accessed 17 March 2017).

7. Rothwell C, Burford B, Morrison J, Morrow G, Allen M, Davies C. Junior doctors prescribing: enhancing their learning in practice. Br J Clin Pharmacol 2012;73:194-202. http://dx.doi.org/10.1111/j.1365-2125.2011.04061.x

8. Peters M, Cate $\mathrm{O}$. Bedside teaching in medical education: a literature review. Perspect Med Educ 2014;3:76-88. https://doi.org/10.1007/s40037-013-0083-y

9. Diemers AD, Van de Wiel MW, Scherpbier AJ, Heineman E, Dolmans DH Pre-clinical patient contacts and the application of biomedical and clinical knowledge. Med Educ 2011;45:280-8.

http://dx.doi.org/10.1111/j.1365-2923.2010.03861.x

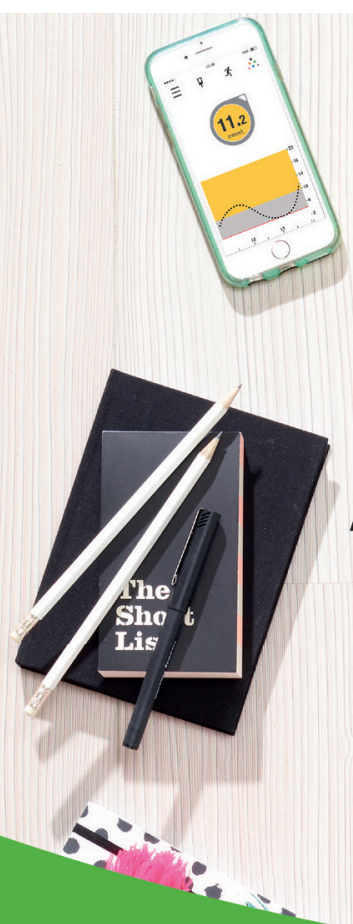

"My daughter has left home

for the first time. I miss her terribly but with the Dexcom Follow* App I can still feel connected, involved and in many ways she is still close.

Amber - Mum of T1D teen Little things. Big difference.
With Dexcom‡, your patients and their families can stay connected with real-time data sharing on compatible smart devices ${ }^{\dagger}$

Discover how at www.dexcom.com/littlethings 